\title{
Presbyopia - A Review of Current Treatment Options and Emerging Therapies
}

\author{
James A Katz' \\ Paul M Karpecki (D) ${ }^{2}$ \\ Alexandra Dorca ${ }^{3}$ \\ Sima Chiva-Razavi ${ }^{4}$ \\ Heather Floyd ${ }^{4}$ \\ Elizabeth Barnes ${ }^{4}$ \\ Mark Wuttke (iD ${ }^{4}$ \\ Eric Donnenfeld (DD ${ }^{5}$ \\ 'The Midwest Center for Sight, Des \\ Plaines, IL, USA; ${ }^{2}$ Kentucky Eye Institute, \\ Lexington, KY, USA; ${ }^{3}$ Favoris AG, Basel, \\ Switzerland; ${ }^{4}$ Novartis Pharma AG, Basel, \\ Switzerland; ${ }^{5}$ Ophthalmic Consultants of \\ Long Island, Garden City, NY, USA
}

Correspondence: Eric Donnenfeld Ophthalmic Consultants of Long Island, 7II Stewart Avenue, Suite 160, Garden City, NY, II530, USA

Email ericdonnenfeld@gmail.com

\begin{abstract}
Presbyopia is a common age-related vision disorder characterized by a progressive inability to focus on near objects. If uncorrected or under-corrected, presbyopia can significantly impact patients' quality of life. Presbyopia represents an area of considerable unmet need due to its rising prevalence worldwide as the population ages, the high proportion of under-treated individuals in some parts of the world, and the limitations of currently available corrective methods. Progressive or bifocal spectacles are associated with peripheral blur, a restricted visual field and impaired depth perception, which have been linked to an increased risk of falls in the elderly. Contact lens options can be difficult to maintain due to the development of age-related dry eye symptoms and reduced manual dexterity. Other corrective methods involve surgical interventions that modify the optics of the cornea, replace the crystalline lens, or attempt to restore active accommodation. While patients undergoing surgery report satisfactory outcomes post-operatively, many of them eventually require reading glasses. Non-invasive therapies with novel mechanisms of action are currently being investigated; these include miotic agents and UNR844, a lipoic acid choline ester. In this narrative review, available evidence on presbyopia prevalence, quality of life impact and risk factors are described, with a focus on observational studies in nonclinical settings. The diagnosis pathway and patient journey in presbyopia are outlined, and various treatment options are analyzed. The data reviewed herein reveals significant gaps in the provision of vision correction for this common condition, with a paucity of effective, non-invasive treatment options broadly accessible to presbyopic individuals.
\end{abstract}

Keywords: presbyopia, epidemiology, patient characterization, vision correction, pharmacological therapies

\section{Plain Language Summary}

This review was carried out to i) explore available evidence on the causes and risk factors of presbyopia, ii) summarize how the condition is currently diagnosed and managed, including residual unmet needs and iii) provide an overview of potential future treatment options that are currently in development. Presbyopia is an age-related decline in the ability to focus on near tasks, thought to be caused by a loss of flexibility, increase in size and hardening of the lens and/ or the muscle fibers surrounding the lens inside the eye. Our research found that the onset of presbyopia may be earlier in women and in individuals who live closer to the equator. Presbyopia onset may also be influenced by an individual's distance glasses prescription. We discovered that presbyopia is typically diagnosed around 50 years of age, with optometrists being the major providers of vision correction. However, current treatment options for presbyopia, which include glasses, contact lenses and surgery, mostly manage the symptom of blurred near vision, without addressing the underlying cause of the condition. This review highlights the need for effective, broadly accessible, non-invasive presbyopic treatment options. 


\section{Introduction}

Presbyopia is a common, age-related vision disorder characterized by a progressive inability to focus on near objects. Presbyopia is hypothesized to be caused by either a weakening of the ciliary muscles or a loss of lens elasticity preventing focal point change. ${ }^{1,2}$ While the etiology of this condition is not fully elucidated, recent research suggests that an increase in lens rigidity is the primary causative mechanism.,

Although corrective measures are available to restore near vision, access to treatment (most often in the form of reading glasses) is limited in some parts of the world. In 2015,826 million of the 1.8 billion people estimated to have functional presbyopia were found to be living with uncorrected near vision impairment because they had no access to vision correction or were utilizing inadequate correction. ${ }^{5}$ Without optical correction, presbyopia can have multiple effects on quality of life, such as problems reading (inability to read fine print, need for increased lighting, diplopia, epiphora, headache fatigue or asthenopia), and other tasks, such as threading a needle or seeing fine details on proximal objects. ${ }^{6}$

This review encapsulates available evidence on presbyopia epidemiology, diagnosis and management, while highlighting the unmet need for an effective, broadly accessible, non-invasive presbyopic treatment options.

\section{Presbyopia: Prevalence and Quality of Life Impact}

The prevalence and severity of presbyopia increases with age, with up to $\sim 85 \%$ of people aged 40 years or older developing presbyopia. ${ }^{5}$ In 2015 , it was estimated that 1.8 billion people globally had presbyopia and the prevalence is expected to peak at approximately 2.1 billion in $2030 .^{5}$ Although the measured prevalence of presbyopia is greater in regions with longer life expectancies, ${ }^{5}$ it is estimated that $94 \%$ of those with significant near vision disability due to uncorrected presbyopia live in developing countries. ${ }^{7}$

Studies have revealed that presbyopia is undercorrected in many countries, with reading glasses available for only $6-45 \%$ of patients living in developing countries. ${ }^{7}$ In these parts of the world, the high prevalence of uncorrected presbyopia is due to a lack of adequate diagnosis and affordable treatment. ${ }^{8-11}$

Uncorrected or under-corrected presbyopia has a substantial impact on quality of life, regardless of the nature of daily activities performed. ${ }^{12}$ However, affected individuals can experience a dramatic increase in productivity in their daily activities when provided with an appropriate correction. ${ }^{13}$ At the same time, in developed countries, the broad accessibility of corrective devices such as reading glasses may mean that potential alternative presbyopic treatment options are often overlooked. ${ }^{14}$ Additionally, dependence on spectacles is one of the main causes of loss of quality of life in people over 45 years of age. ${ }^{15}$

\section{Presbyopia Risk Factors}

\section{Environment}

The first symptoms of presbyopia are typically experienced around 40 years of age in Western societies, with an earlier age of onset reported in countries closer to the equator, such as Central/South American countries. ${ }^{16}$ It has been previously hypothesized that premature degradation of the crystalline lens may be caused by ultraviolet radiation exposure, thus contributing to premature onset presbyopia. $^{17-19}$

\section{Refractive Status}

There is a scarcity of literature relating to baseline refractive error in presbyopes. A prospective study of 473 subjects presenting with presbyopia at a rural tertiary teaching hospital in India revealed just under half (49.7\%) were emmetropes, $30.3 \%$ had hyperopic correction, and $20 \%$ had a myopic correction. ${ }^{20}$ A later study carried out in 1191 urban Chinese participants (mean age 50.4 years; $52.9 \%$ female) found a significantly higher prevalence $(52.2 \%)$ and incidence $(78.8 \%)$ of functional presbyopia among hyperopic individuals compared to the rest of the cohort. ${ }^{9}$ Results from this study also revealed a considerably lower overall prevalence of functional presbyopia $(25.2 \%)$ compared to values reported in other studies; attributed to the socioeconomic gap between urban and rural areas. ${ }^{9}$

While hyperopia and presbyopia have different etiologies, low rates of undiagnosed hyperopia would manifest as an earlier need for near-vision correction with the onset of presbyopia. $^{21}$

\section{Sex}

Women over 40 years of age have higher rates of presbyopia than men in the same age group. ${ }^{21}$ The increased need for presbyopia correction in women is hypothesized to be caused by differences in tasks performed and viewing 
distance requirements, rather than physiological gender differences in accommodation mechanisms. ${ }^{21}$

\section{Patient Diagnosis and Eye Care Provision}

Globally, optometrists are the major providers of vision correction, though mainly in private practice rather than in community settings. ${ }^{22}$ However, there are substantial differences in optometric service provision between countries. Most US optometrists encounter presbyopes on a daily basis in private practices, ${ }^{21}$ compared to European primary eye care models which are more heterogeneous. Within Europe, eye care in France is almost exclusively provided by ophthalmologists, while optometrists are the main primary eye care providers in the UK. The German system is a mixed model, where ophthalmologists as well as optometrists provide essential elements of primary eye care. ${ }^{23}$ The regulatory framework, education and scope of practice of ophthalmologists are similar in France, Germany, and the UK. However, the numbers of active ophthalmologists differ significantly between these countries, leading to differing roles for ophthalmologists in primary eye care. $^{23}$

Presbyopia is typically diagnosed around 50 years of age, with case studies indicating that individuals residing in developed countries who have never had an eye examination before 50 years of age are likely to be emmetropic or hyperopic. ${ }^{16}$ In India, patients with myopia have been found to seek intervention for presbyopia later than emmetropes and hyperopes within the same age group. ${ }^{5}$ In some cases, a decrease in the age-specific prevalence of presbyopia has been reported as a result of the increasing prevalence of myopia, which decreases the accommodative need of individuals without optical correction. ${ }^{5}$

Before presenting for an eye exam, presbyopes often self-diagnose and may resort to over the counter (OTC) reading (or magnifying) spectacles as an initial solution to a reduction in near visual acuity. ${ }^{6}$ This may be influenced by economic status, which was found to impact the frequency of accessing eye care services and obtaining spectacles among presbyopes in an American community. ${ }^{24}$

With rising life expectancy, the increasing prevalence of age-related ocular conditions, such as glaucoma, diabetic retinopathy, age-related macular degeneration and presbyopia is anticipated to pose a challenge to eye care service providers in Europe, especially as the number of ophthalmologists are decreasing in some countries. ${ }^{25}$

\section{Presbyopic Treatment Options}

Methods to correct presbyopia include both fixed- and variable focus lens systems, as well as surgical interventions that modify the optics of the cornea, replace the crystalline lens, or attempt to at least partially restore active accommodation, with ongoing efforts to improve the presbyopic visual experience. ${ }^{26}$

\section{Optical Appliances Spectacles}

Spectacles are generally assumed to be the most accessible intervention for correcting the symptoms of presbyopia, however no currently available spectacle lens can fully restore the dynamic range of accommodation in the aging eye. ${ }^{14,27}$ Single near-vision spectacles, designed with a single focal point throughout the entire area of the lens appropriate to the distance of the object viewed, correct sight at one distance only, therefore requiring removal of spectacles or a separate pair of spectacles for distance viewing. ${ }^{27}$

Bifocal, trifocal or progressive addition spectacle lenses (PALs) incorporate zones of various optical powers for viewing objects at chosen specific distances. As multiple prescriptions can be combined in one lens, variable lens systems are advantageous as typically only one pair of spectacles is required. ${ }^{14,27}$ Compared to single vision lenses, variable lens systems are typically more expensive and have restricted optical zones, ${ }^{27}$ which can impact individuals' subjective visual experiences while driving and performing workplace tasks. ${ }^{28,29}$

\section{Contact Lenses}

Contact lens options for presbyopia include single vision distance contact lens correction with reading spectacles providing the required near addition, monovision correction, or a bi-/multifocal correction based on alternating or simultaneous image principles. ${ }^{26,30}$

The combination of a single vision soft or rigid gas permeable (RGP) contact lens correction with reading spectacles can provide optimum vision at distance and near with less expense and fitting complications compared to multifocal options. However, patients are still inconvenienced by taking on and off glasses to read. ${ }^{31}$

Monovision and enhanced monovision correction involves correcting one eye for optimal distance viewing and the alternate eye with a single vision near or bi-/ multifocal contact lens. ${ }^{31}$ Although typically less expensive and perceived as easier to fit compared to multifocal 
lens designs, a major limitation with monovision is a reduction in stereopsis and contrast sensitivity, ${ }^{32-35}$ both important for critical visual tasks such as driving. ${ }^{36}$

Multifocal contact lenses accommodate multiple refractive prescriptions. Contact lens selection and a comprehensive pre-fitting evaluation are important in multifocal lens wear, due to patient satisfaction relying strongly on lens centration, pupil size, ocular optics, and neural adaptation. ${ }^{37,38}$ The success of multifocal contact lenses can vary substantially across individuals due to differences to blur tolerance, ocular aberrations and neural adaptation. ${ }^{37}$

Although the extent to which multifocal and monovision lenses are prescribed for presbyopia varies considerably by country, an international survey report in 2011 revealed the rate of multifocal soft contact lens prescribing was over 3 times greater than that for monovision soft contact lenses ( $25 \%$ compared to $7 \%$ ), with survey results revealing an overall low rate of presbyopic contact lenses prescribing. ${ }^{39}$ However, in more recent years the multifocal market share has grown due to technological advances in lens design, materials and manufacturing methods, as well as the availability of various lens replacement options and the increased practitioner confidence. ${ }^{38-41}$ Although such technological advances may attempt to satisfy the complexity of presbyopic treatment requirements, the development of age-related conditions such as dry eye may hinder patients' lens-wearing experience in terms of vision and comfort. ${ }^{42,43}$

Females are more likely than males to wear contact lenses for presbyopia, owing in part to cosmetic reasons. ${ }^{39,44}$ In a survey of 14,690 patients in the UK, women were twice as likely to have a presbyopic contact lens correction, ${ }^{45}$ and an Irish study found that $65 \%$ of the patients ( $\mathrm{N}=97$ ) undergoing surgical compensation of presbyopia and additional ametropia were female. ${ }^{46}$

\section{Surgical Options}

The increased use of digital devices, coupled with an increase in patients continuing to work past retirement, has resulted in permanent vision correction options becoming particularly attractive to the aging population. ${ }^{47}$ Advancements in lens design alongside an increased variety of surgical options over the past decades have also led to its increased popularity. ${ }^{48-50}$

\section{Refractive Lens Exchange}

Refractive lens exchange (RLE), in which the natural crystalline lens in the eye is replaced with an intra-ocular lens (IOL), can effectively reduce or mitigate the need for reading glasses by using monovision, multifocal, extended depth of focus, or accommodating intraocular lens implants (Table 1). ${ }^{51}$ Monovision single vision lens implants are only appropriate for certain patient categories, and effective patient selection is crucial for a successful outcome of the procedure. ${ }^{52,53}$ Current multifocal IOL designs predominantly provide good visual outcomes, ${ }^{54}$ with trifocal toric IOLs found to provide significantly better near vision than extended depth of focus IOLs while providing similar intermediate and distance VA outcomes. ${ }^{55}$ Accommodating intraocular lens implants respond to ciliary body contraction, thus inducing accommodation, although current designs induce some inevitable side effects, such as limited amplitude of accommodation and a high rate of posterior capsular opacification. ${ }^{56} \mathrm{New}$ generation accommodating IOLs are now under investigation. ${ }^{57} \mathrm{~A}$ recent development in RLE is the light adjustable lens, which permits post-operative titrations in IOL power after the eye has healed, facilitating customization and optimization of the lens to achieve the desired prescription (Table 1). ${ }^{58}$

In terms of patient satisfaction after surgical correction for presbyopia, a multicenter study in 2015 reported that three months after undergoing RLE with a zonal refractive IOL, over $90 \%$ of (220) patients found the procedure improved their lives, and $93.5 \%$ were willing to

Table I Current Surgical Options for Presbyopia

\begin{tabular}{|l|l|}
\hline Site & Surgical Options \\
\hline Cornea $^{65,108-110}$ & - Monovision (LASIK) \\
& - Presbyopic LASIK* (multifocal laser ablation) \\
- Photorefractive keratectomy (PRK) \\
- Intracor Femtosecond Laser (LASIK) \\
- KAMRA ${ }^{\text {TM }}$ Corneal Inlay \\
- Conductive keratoplasty
\end{tabular}

Note: *Not FDA-approved

Abbreviations: IOL, intraocular lens; LASIK, laser-assisted in situ keratomileusis. 
recommend it to friends and family. ${ }^{51}$ Similarly, in a more recent case series study, $96 \%$ of emmetropic participants would recommend unilateral RLE with multifocal IOL implantation to friends and family. ${ }^{59}$ A separate retrospective chart review of 29 patients implanted with a diffractive multifocal IOL found that all patients who underwent bilateral RLE were spectacle-free at their 6 month check. Among these, the group with habitual spectacle use pre-operatively were the most satisfied with their post-operative visual performance. ${ }^{60}$ In a medical record study of 304 patients implanted bilaterally with multifocal IOLs, patients' scores on the "Freedom from Spectacles Value Scale" questionnaire were between 3.8 and 4.4 (of a maximum of 5), indicating a high degree of satisfaction following surgery. ${ }^{61}$ In contrast, the most identifiable causes of dissatisfaction after implantation of presbyopiacorrecting IOLs are residual refractive errors and dry eye symptoms. $^{62}$

Recent results on the implantation of a presbyopic phakic intraocular contact lens in the posterior chamber of 16 eyes ( 8 patients) have demonstrated that patients had good visual acuity and were fully independent of spectacles for both far and near distance four weeks following surgery. No significant change in intraocular pressure and no complaints of halo or glare were reported, with overall high patient satisfaction regarding the quality of vision. However, longer-term data are needed to assess the outcomes of this intervention. ${ }^{63}$

\section{Corneal Procedures for Presbyopia}

Other surgical options for presbyopic individuals involve procedures such as corneal inlays and laser surgery (Table 1).

Corneal inlays consist of a minimally invasive surgical implantation of an inlay into the corneal stroma of one eye and has advantages including reversibility and repeatability while providing high levels of satisfaction and spectacle independence for near vision. ${ }^{14,53,64-67}$ The disadvantages of corneal inlays are a potential compromise of night vision and distance vision, and the long-term potential for corneal haze development. The three types of corneal inlays are corneal reshaping inlays, refractive inlays, and small-aperture inlays. ${ }^{64}$ The Raindrop Near Vision Inlay, a corneal reshaping transparent hydrogel implant, was recalled by the FDA in 2018, due to an increased risk of corneal haze observed in a postapproval study of 150 patients who were followed for 5 years after implantation. ${ }^{68} \mathrm{KAMRA}^{\mathrm{TM}}$ (Acufocus, Inc.), an FDA approved small-aperture inlay, currently has more data supporting its efficacy and safety than of any other inlay. In a cohort of 32 emmetropic presbyopic eyes, longterm results of monocular KAMRA ${ }^{\mathrm{TM}}$ inlay implantation showed maintenance of near vision acuity, with only one inlay removed at 36 months. ${ }^{69}$ In a more recent study, $\mathrm{KAMRA}^{\mathrm{TM}}$ was found to be safe and effective among 507 emmetropic presbyopes, however, 44 (8.7\%) inlays were removed from the full cohort within 3 years. ${ }^{70}$ In contrast to monovision which also targets one eye, inlays do not compromise distance visual acuity, however smallaperture corneal inlays such as $\mathrm{KAMRA}^{\mathrm{TM}}$ can restrict light entering the eye which may reduce contrast and night vision.

While patients undergoing surgical interventions generally report satisfactory outcomes post-operatively, they may experience significant regression over time, with some reverting to their pre-operative refractive state. ${ }^{71}$ Many patients may eventually need reading glasses again after corneal inlay surgery, ${ }^{64}$ and over half of patients undergoing unilateral RLE were found to require spectacles post-operatively. ${ }^{60}$ Surgical correction strategies for presbyopia may also disrupt the corneal epithelium and ocular surface, which can impact outcomes and exacerbate dryness in the aging presbyopic eye. ${ }^{72}$

In terms of laser surgery, monovision or multifocal laser in situ keratomileusis (LASIK) and photorefractive keratectomy (PRK) can be used to remove corneal tissue and reshape the cornea to reduce the need for reading glasses in presbyopic individuals (Table 1). Monovision laser vision correction, in which one eye is optically corrected for distance and the other eye for near vision, often results in reduced binocular visual acuity and stereopsis. ${ }^{73}$ In saying that, monovision laser correction in myopic individuals has been shown to result in sustained vision outcomes and good patient satisfaction. ${ }^{52}$ Multifocal (or presbyopic) LASIK and PRK aim to correct vision by changing the refractive power of the cornea by either increasing depth of focus by ablation of the peripheral cornea (transitional multifocality and peripheral presbyLasik) or by creating a bifocal cornea (central presbyLasik). $^{74}$

LASIK is also useful in that it can provide a minimally invasive option for conversion to bilateral distance correction or enhancement of the distance eye following surgical monovision correction, as patients who have had surgically induced monovision appear to be more sensitive to 
changes in their distance eye, and thus are more likely to request enhancement for small residual refractive errors. ${ }^{64}$

\section{Scleral Correction Procedures for Presbyopia}

Scleral approaches are based on the Schachar's theory of accommodation and attempt to preserve or restore the accommodative ability of the eye by expanding the equatorial scleral diameter overlying the ciliary body and restoring zonular tension. ${ }^{75}$ Although, the theoretical justification of such procedures remains controversial, there has been increasing interest in scleral interventions, which use laser scleral micro-excisions and scleral micro-inserts (Table 1$)^{75}$

\section{Unmet Needs of Presbyopic Patients}

Even though the global prevalence of presbyopia is continuing to increase with population growth, ${ }^{5}$ patients' experience of presbyopic treatment options has been insufficiently investigated, although there is increasing interest in the topic. A recent social media listening study found that individuals with presbyopia experienced difficulties with reading and electronic devices, and felt inconvenienced by the use of varifocal glasses and contact lenses. ${ }^{76}$ An online survey of pre-presbyopic and presbyopic volunteers perceived comfort and convenience of their optical correction as more important than cost, with spectacles preferred over multifocal contact lenses for near vision correction. ${ }^{77}$ Multifocal IOLs have been shown to improve patients' quality of life, in contrast to patient satisfaction following presbyopic LASIK, which was found to be similar to reading glasses. ${ }^{78}$

All currently available treatment methods require the patient to accept some compromises in the quality and flexibility of vision offered at different distances. ${ }^{26}$ However, could such compromises increase the risk of falls and injury ${ }^{79}$ Falls among presbyopic age cohorts are identified as a significant public health concern. ${ }^{80}$ Presbyopes wearing multifocal glasses can experience blurred vision when viewing distant objects through the lower part of the lens, as well as impaired depth perception, leading to a higher incidence of falls. ${ }^{81,82} \mathrm{~A}$ one-year prospective cohort study of 156 people aged 63 to 90 found that multifocal spectacle wearers were twice as likely to fall as those not wearing multifocal spectacles, due to impaired depth perception and edge-contrast sensitivity, especially in unfamiliar settings outside the home or when negotiating stairs. ${ }^{83}$ A study of healthy individuals found that monocular blur in monovision correction led to significant reductions in stereoacuity and spatial perception. ${ }^{84}$ However, another study reported that spectacle magnification rather than lens blur was responsible for step negotiation and mobility problems experienced by elderly glass wearers. ${ }^{85}$ The Visual Intervention Strategy Incorporating Bifocal \& Long-distance Eyewear (VISIBLE) randomized controlled trial $(\mathrm{N}=606$ patients, mean age 80 years) found that replacing multifocal spectacles with single vision spectacles for walking and outdoor activities in elderly individuals resulted in an $8 \%$ reduction in falls. ${ }^{86}$ The provision of intermediate addition multifocal spectacles (of $\sim 1.00-1.25 \mathrm{D}$ ) instead of a full addition lens, worn inside and outside the home, has been proposed to help reduce falls whilst avoiding continuous switching of glasses in elderly populations. ${ }^{87}$ Furthermore, some clinicians recommend only prescribing partial changes in refractive error in older patients to help adaptation. ${ }^{72}$ However, these recommendations are not evidence-based, and further research is needed on the effect of ocular or spectacle magnification on mobility and falls.

\section{Future Outlook for Presbyopia}

Topical pharmacological options currently being investigated can be defined under two general categories: those working via pupil modulation and those aiming to restore accommodation. ${ }^{88}$

\section{Symptomatic Relief of Presbyopia Symptoms via Pupil Modulation}

The majority of formulations under development are included in the first group, which involves increasing the depth of field by parasympathetic-mediated miosis and ciliary muscle stimulation, or lens softening to temporarily ameliorate the symptoms of presbyopia. ${ }^{89,90}$ These therapies, which include pilocarpine, carbachol, acelcedine/brimonidine tartrate, FOV Tears, AGN-190584, AGN-199201, PRX ophthalmic solution, Nyxol, CSF-1 and VISION-1, rely on improving near vision for a period of 6 to 8 hours (Table 2). ${ }^{75,89-101}$ Pilocarpine formulations have varying concentrations, from less than $0.5 \%$ to above $1 \%$. Higher concentrations may provide a longer duration of effect, whereas lower concentrations may show less adverse events or increased comfort. ${ }^{102}$ The Phase 3 trials (NCT03857542 and NCT03804268) of AGN-190584, a miotic agent, were completed in late 2019, and demonstrated a significant 
Table 2 Topical Pharmacological Options Currently Under Investigation, Defined as Those Working via Pupil Modulation or Aiming to Restore Accommodation

\begin{tabular}{|c|c|c|c|c|}
\hline $\begin{array}{l}\text { Compound Name and } \\
\text { Formulation }\end{array}$ & $\begin{array}{l}\text { Mechanism } \\
\text { of Action }\end{array}$ & $\begin{array}{l}\text { Clinical } \\
\text { Development } \\
\text { Status }\end{array}$ & Key Findings & $\begin{array}{l}\text { Manufacturerl } \\
\text { ClinicalTrials.gov }\end{array}$ \\
\hline \multicolumn{5}{|l|}{ Pupil modulation } \\
\hline Carbachol/brimonidine & Miotic & Phase 2 & $\begin{array}{l}\text { Statistically significant improvement in NVA } \\
\text { over placebo; effect was maintained over } 3 \\
\text { months }(\mathrm{N}=48)\end{array}$ & $\begin{array}{l}\text { Therapeutics press } \\
\text { release } 2020^{91} \\
\text { Abdelkader } 2015^{90} \\
\text { Visus }\end{array}$ \\
\hline $\begin{array}{l}\text { FOV Tears (pilocarpine/ } \\
\text { phenylephrine/ } \\
\text { polyethyleneglycol/nepafenac/ } \\
\text { pheniramine/naphazoline) }\end{array}$ & Miotic & $\begin{array}{l}\text { Phase I; currently } \\
\text { available in Columbia, } \\
\text { with Phase } 2 \text { studies } \\
\text { ongoing }\end{array}$ & $\begin{array}{l}\text { Pupil size initially decreased and NVA improved } \\
\text { up to } 5 \mathrm{~h}(\mathrm{~N}=14)\end{array}$ & Renna et al, $2016^{89}$ \\
\hline $\begin{array}{l}\text { AGN-I } 90584 \text { ophthalmic } \\
\text { solution (pilocarpine) }\end{array}$ & Miotic & $\begin{array}{l}\text { Phase } 3 \text { complete } \\
\text { FDA registration }\end{array}$ & $\begin{array}{l}\text { A statistically significant greater proportion of } \\
\text { participants treated with } A G N-190584 \text { gained } 3 \\
\text { lines or more in mesopic, high contrast, } \\
\text { binocular DCNVA }(N=327)\end{array}$ & $\begin{array}{l}\text { Allergan press } \\
\text { release } 2020^{92} \\
\text { NCT03857542 }\end{array}$ \\
\hline $\begin{array}{l}\text { AGN-I9920I ophthalmic } \\
\text { solution (pilocarpine/ } \\
\text { oxymetazoline) }\end{array}$ & Miotic & Phase 2 & $\begin{array}{l}\text { Up to } 70 \% \text { of patients had at least a } 2 \text {-line } \\
\text { improvement in uncorrected NVA }(N=|5|)\end{array}$ & NCT02780II $5^{94}$ \\
\hline $\begin{array}{l}\text { PRX ophthalmic solution } \\
\text { (aceclidine/tropicamide) }\end{array}$ & Miotic & Phase $2 b$ & $\begin{array}{l}\text { Primary endpoint vs placebo was met; duration } \\
\text { of effect was approximately } 7 \mathrm{hrs}\end{array}$ & $\begin{array}{l}\text { Presbyopia } \\
\text { Therapies press } \\
\text { release } 2018^{95}\end{array}$ \\
\hline $\begin{array}{l}\text { Nyxol (phentolamine } \\
\text { ophthalmic solution)/ } \\
\text { pilocarpine }\end{array}$ & Miotic & Phase 2 & $\begin{array}{l}\text { Primary endpoint is percentage of subjects with } \\
\geq 15 \text { letters of improvement in photopic } \\
\text { binocular DCNVA }\end{array}$ & $\begin{array}{l}\text { Ocuphire }^{96} \\
\text { NCT04675I51 }\end{array}$ \\
\hline CSF-I & Miotic & Phase $2 \mathrm{~b}$ complete & $\begin{array}{l}\text { Statistically significant improvement in DCNVA } \\
\text { of a } 3 \text {-line or greater gain. }\end{array}$ & $\begin{array}{l}\text { Orasis } \\
\text { Pharmaceuticals } \\
\text { press release }^{98} \\
\text { NCT0388501 } 1^{99}\end{array}$ \\
\hline VISION-I (pilocarpine) & Miotic & Phase 3 & $\begin{array}{l}\text { Primary outcome is the proportion of subjects } \\
\text { gaining } \geq 15 \text { letters in mesopic, high contrast, } \\
\text { binocular distance corrected near visual acuity } \\
\text { (DCNVA) [Time Frame: } 120 \text { minutes post- } \\
\text { dosing] }\end{array}$ & $\begin{array}{l}\text { Eyenovia }^{100} \\
\text { NCT04657172 }\end{array}$ \\
\hline \multicolumn{5}{|c|}{ Treatments for the underlying cause of presbyopia } \\
\hline UNR844 & $\begin{array}{l}\text { Lipoic acid } \\
\text { choline ester }\end{array}$ & Phase $1 / 2$ & $\begin{array}{l}\text { Bilateral DCNVA improved, with } 53.1 \% \\
\text { UNR844 vs } 21.7 \% \text { placebo subjects gaining } \geq 10 \\
\text { letters. Improvements in DCNVA were } \\
\text { sustained at } 5 \text { and } 7 \text { months after UNR844 } \\
\text { dosing ceased. }\end{array}$ & $\begin{array}{l}\text { Novartis } \\
\text { NCT02516306 }\end{array}$ \\
\hline UNR844 & $\begin{array}{l}\text { Lipoic acid } \\
\text { choline ester }\end{array}$ & Phase $2 \mathrm{a}$ & $\begin{array}{l}\text { Bilateral DCNVA improved, with a four-letter } \\
\text { median difference between UNR844 vs placebo } \\
\text { groups ( } P=0.0924) \text {, and no meaningful } \\
\text { differences in side effects }\end{array}$ & $\begin{array}{l}\text { Novartis } \\
\text { NCT038096 I I } 105,112\end{array}$ \\
\hline
\end{tabular}

Notes: $\geq$, greater than or equal to; (DC)NVA, (distance-corrected) near vision acuity; N, study population sample size; P, statistically significance; vs, versus. This table only includes products for which clinical data is available. 
improvement in near vision and patient-reported outcomes (PROs) with a once-daily bilateral administration of AGN190584 ophthalmic solution for 30 days compared with placebo in presbyopic adults aged 40 to 55 years. The most common adverse effects were headache, conjunctival hyperaemia, blurred vision and eye pain, reported by $\geq 3 \%$ of AGN-190584 treated participants. ${ }^{92}$ A further recent nonrandomized, case series, 8-year retrospective study found that pilocarpine/diclofenac eye drops were an efficient treatment for emmetropic or presbyopic individuals, providing spectacle independence for near visual tasks. ${ }^{103}$ A combination topical preparation of carbachol and brimonidine has been shown to provide a longer duration of action in correcting presbyopia than pilocarpine. ${ }^{104}$

\section{Treatments for the Underlying Cause of Presbyopia}

The second group includes pharmaceutical treatments exploring novel mechanisms of action in presbyopia, in order to address the underlying causes of the condition, by investigating age-related lens stiffness and associated increasing lens disulfide content. $^{3,105}$ The prodrug UNR844 is currently under investigation and in a Phase $1 / 2$ study (NCT02516306) comprising 75 patients aged 45-55 years, the UNR844 treatment group gained an average of approximately one line (5 letters) over placebo and two lines (10 letters) over baseline after 90 days of treatment, with the benefit maintained until the final assessment, carried out 7 months after cessation of treatment (Table 2). ${ }^{106}$ The results from this study demonstrate UNR844 to be a well-tolerated, effective pharmacological intervention for improving near visual acuity. These results, along with the subsequent Phase 2 a study results, support the further development of this therapeutic approach as a potential treatment for presbyopia. ${ }^{105}$

A further new chemical entity developed by ViewPoint Therapeutics targets protein misfolding and aggregation to treat and prevent lens disorders; this approach is being tested in cataract and potentially presbyopia. ${ }^{107}$

Such approaches present an attractive alternative to near lenses or surgical interventions and, if successful, would mark a milestone in the management of presbyopia. ${ }^{32}$ However, while progress has been made in the development of non-invasive therapies, none of these are sufficiently developed to become routine interventions. $^{27}$

\section{Conclusion}

Presbyopia is a common condition with increasing prevalence in a globally aging population. Yet, all currently available presbyopic correction methods require the patient to accept compromises in the quality and flexibility of vision offered at different distances. Currently, there is no major pharmacologic therapy to address the unmet needs of presbyopic patients. As uncorrected or suboptimally corrected presbyopia can have a considerable impact on patients' daily activities and quality of life, a unique and ideal solution, or a treatment that restores true accommodation, is a priority.

\section{Acknowledgments}

Medical writing support was provided by Saoirse McCrann PhD, Ileana Stoica, PhD, and Theresa Reape, $\mathrm{PhD}$, all of Novartis Ireland Ltd, and funded by Novartis Pharma AG.

\section{Funding}

The funding of this study was provided by Novartis Pharma AG, Basel, Switzerland.

\section{Disclosure}

JK reports consultant fees from Alcon, Allergan, Novartis and Refocus. PMK reports consultant and/or research fees from Alcon, AbbVie, Allergan, Bausch \& Lomb, Eyenovia, Johnson \& Johnson Vision, Novartis, Ocuphire, Orasis, and Visus. AD is an employee of Favoris AG, providing services to Novartis Pharma AG. ED reports consultant fees from Alcon, Allergan, Johnson \& Johnson, LenSGen, Novartis, Orasis, and Visus. SCR, HF, EB and MW are employees of Novartis Pharma AG. The authors report no other conflicts of interest in this work.

\section{References}

1. Glasser A, Campbell MC. Biometric, optical and physical changes in the isolated human crystalline lens with age in relation to presbyopia. Vision Res. 1999;39(11):1991-2015. doi:10.1016/S0042-6989(98) 00283-1

2. Heys K, Cram LS, Roger J. University of Wollongong. Massive increase in the stiffness of the human lens nucleus with age: the basis for presbyopia? Molecular Vision. 2004;10:956-963.

3. Garner WH, Garner MH. Protein disulfide levels and lens elasticity modulation: applications for presbyopia. Invest Ophthalmol Vis Sci. 2016;57(6):2851-2863. doi:10.1167/iovs.15-18413

4. David G, Pedrigi RM, Humphrey J. Accommodation of the human lens capsule using a finite element model based on nonlinear regionally anisotropic biomembranes. Computer Methods Biomechanics Biomed Eng. 2017;20(3):302-307. doi:10.1080/10255842.20 16.1228907 
5. Fricke TR, Tahhan N, Resnikoff S, et al. Global Prevalence of Presbyopia and Vision Impairment from Uncorrected Presbyopia: systematic Review, Meta-analysis, and Modelling. Ophthalmology. 2018;125(10):1492-1499. doi:10.1016/j.ophtha.2018.04.013

6. Mancil G, Bailey I, Brookman K. Optometric clinical practice guideline care of the patient with presbyopia. Reference guide for clinicians. Am Optometric Assoc. 2011;1:458.

7. Goertz AD, Stewart WC, Burns WR, Stewart JA, Nelson LA. Review of the impact of presbyopia on quality of life in the developing and developed world. Acta Ophthalmol. 2014;92 (6):497-500. doi:10.1111/aos.12308

8. Chan VF, MacKenzie GE, Kassalow J, Gudwin E, Congdon N. Impact of presbyopia and its correction in low-and middle-income countries. Asia Pacific J Ophthalmol. 2018;7 (6):370-374. doi:10.22608/APO.2018449

9. Han X, Lee PY, Liu C, He M. Distribution and progression of add power among people in need of near correction. Clin Experiment Ophthalmol. 2018;46(8):882-887. doi:10.1111/ceo.13301

10. Holden BA, Fricke TR, Ho SM, et al. Global vision impairment due to uncorrected presbyopia. Arch Ophthalmol. 2008;126 (12):1731-1739. doi:10.1001/archopht.126.12.1731

11. Gajapati CV, Pradeep A, Kakhandaki A, Praveenchandra R, Rao S. Awareness of Presbyopia among Rural Female Population in North Karnataka. J Clin Diagnostic Res. 2017;11 (9):NC01. doi:10.7860/JCDR/2017/26125.10608

12. Patel I, Munoz B, Burke AG, et al. Impact of presbyopia on quality of life in a rural African setting. Ophthalmology. 2006;113(5):728-734. doi:10.1016/j.ophtha.2006.01.028

13. Reddy PA, Congdon N, MacKenzie G, et al. Effect of providing near glasses on productivity among rural Indian tea workers with presbyopia (PROSPER): a randomised trial. Lancet Global Health. 2018;6(9):e1019-e1027. doi:10.1016/S2214-109X(18)30329-2

14. Wolffsohn JS, Davies LN. Presbyopia: effectiveness of correction strategies. Prog Retin Eye Res. 2019;68:124-143.

15. Bilbao-Calabuig R, Gónzalez-López F, Llovet-Rausell A, OrtegaUsobiaga J, Fernández VT, Llovet-Osuna F. Lens-based surgical correction of presbyopia. Where are we in 2020? Arch de la Sociedad Española de Oftalmología. 2020.

16. Carlson NB, Aurora Denial O. Hyperopia and presbyopia: a teaching case report. Optometric Educ. 2017;42(3):78.

17. Weale RA. Epidemiology of refractive errors and presbyopia. Surv Ophthalmol. 2003;48(5):515-543. doi:10.1016/S00396257(03)00086-9

18. Stevens M, Bergmanson J. Does sunlight cause premature aging of the crystalline lens? J Am Optom Assoc. 1989;60(9):660-663.

19. Sliney DH. Geometrical gradients in the distribution of temperature and absorbed ultraviolet radiation in ocular tissues. Dev Ophthalmol. 2002;35:40-59.

20. Babu PS, Dhanunjaya A, Amaresh G. Demographic pattern of presbyopia in a tertiary teaching hospital. J Evolution Med Dental Sci. 2015;4:650-657. doi:10.14260/jemds/2015/95

21. Hickenbotham A, Roorda A, Steinmaus C, Glasser A. Metaanalysis of sex differences in presbyopia. Invest Ophthalmol Vis Sci. 2012;53(6):3215-3220. doi:10.1167/iovs.12-9791

22. Oriahi M. The Importance Of Epidemiology In Optometry. J Nigerian Optometric Assoc. 2009;15:48-51.

23. Thomas D, Weegen L, Walendzik A, Wasem J, Jahn R Comparative analysis of delivery of primary eye care in three European countries. Available from: https://www.ecoo.info/wp-content/uploads/2012/ 07/WASEMstudyWebsite.pdf. Accessed 3 January, 2021.

24. Wubben T, Wolfe G, Guerrero C, Korcz WJ, Ramsey DJ. Near visual acuity in an inner city Hispanic community: understanding the barriers and benefits of correction. Community Eye Health. 2014;27(86):41.
25. Doan B, Lévy D, Pavot J. Demographic forecasts of medical workforce supply in France (2000-2050). What numerus clausus for what future? Cahiers De Sociologie et de Démographie Médicales. 2004;44(1):101-148.

26. Charman WN. Developments in the correction of presbyopia I: spectacle and contact lenses. Ophthalmic Physiol Optics. 2014;34 (1):8-29. doi:10.1111/opo.12091

27. Charman WN. Non-surgical treatment options for presbyopia. Expert Rev Ophthalmol. 2018;13(4):219-231. doi:10.1080/ 17469899.2018.1506330

28. Sánchez-Brau M, Domenech-Amigot $\mathrm{B}$, Brocal-Fernández $\mathrm{F}$, Quesada-Rico JA, Seguí-Crespo M. Prevalence of Computer Vision Syndrome and Its Relationship with Ergonomic and Individual Factors in Presbyopic VDT Workers Using Progressive Addition Lenses. Int J Environ Res Public Health. 2020;17(3):1003. doi:10.3390/ijerph17031003

29. Chu BS, Wood JM, Collins MJ. Effect of presbyopic vision corrections on perceptions of driving difficulty. Eye Contact Lens. 2009;35(3):133-143. doi:10.1097/ICL.0b013e3181a1435e

30. Pérez-Prados R, Piñero DP, Pérez-Cambrodí RJ, Madrid-Costa D. Soft multifocal simultaneous image contact lenses: a review. Clin Exp Optometry. 2017;100(2):107-127. doi:10.1111/cxo.12488

31. Bennett ES. Contact lens correction of presbyopia. Clin Exp Optometry. 2008;91(3):265-278. doi:10.1111/j.14440938.2007.00242.x

32. Jain S, Arora I, Azar DT. Success of monovision in presbyopes: review of the literature and potential applications to refractive surgery. Surv Ophthalmol. 1996;40(6):491-499. doi:10.1016/ S0039-6257(96)82015-7

33. Kirschen DG, Hung CC, Nakano TR. Comparison of suppression, stereoacuity, and interocular differences in visual acuity in monovision and acuvue bifocal contact lenses. Optom Vis Sci. 1999;76 (12):832-837. doi:10.1097/00006324-199912000-00018

34. Rajagopalan AS, Bennett ES, Lakshminarayanan V. Visual performance of subjects wearing presbyopic contact lenses. Optom Vis Sci. 2006;83(8):611-615. doi:10.1097/01.opx.0000232185.00091.45

35. Collins MJ, Brown B, Bowman KJ. Contrast sensitivity with contact lens corrections for presbyopia. Ophthalmic Physiol Opt. 1989;9(2):133-138. doi:10.1111/j.1475-1313.1989.tb00832.x

36. Owsley C, McGwin G. Vision and driving. Vision Res. 2010;50 (23):2348-2361. doi:10.1016/j.visres.2010.05.021

37. Remón L, Pérez-Merino P, Macedo-de-araújo RJ, Amorim-desousa AI, González-Méijome JM. Bifocal and Multifocal Contact Lenses for Presbyopia and Myopia Control. J Ophthalmol. 2020;2020:8067657. doi:10.1155/2020/8067657

38. Pérez-Prados R, Piñero DP, Pérez-Cambrodí RJ, Madrid-Costa D. Soft multifocal simultaneous image contact lenses: a review. Clin Exp Optometry. 2017;100(2):107-127.

39. Morgan PB, Efron N, Woods CA. Consortium ICLPS. An international survey of contact lens prescribing for presbyopia. Clin Exp Optometry. 2011;94(1):87-92. doi:10.1111/j.14440938.2010.00524.x

40. Jones D, Woods C, Jones L, Efron N, Morgan P. A sixteen year survey of Canadian contact lens prescribing. Contact Lens Anterior Eye. 2016;39(6):402-410. doi:10.1016/j. clae.2016.09.002

41. Efron N, Nichols JJ, Woods CA, Morgan PB. Trends in US contact lens prescribing 2002 to 2014. Optometry Vision Sci. 2015;92(7):758-767. doi:10.1097/OPX.0000000000000623

42. Rueff EM, Varghese RJ, Brack TM, Downard DE, Bailey MD. A survey of presbyopic contact lens wearers in a university setting. Optometry Vision Sci. 2016;93(8):848-854. doi:10.1097/ OPX.0000000000000881 
43. Kandel H, Khadka J, Fenwick EK, et al. Constructing item banks for measuring quality of life in refractive error. Optometry Vision Sci. 2018;95(7):575-587. doi:10.1097/OPX.0000000000001246

44. Rueff EM, Bailey MD. Presbyopic and non-presbyopic contact lens opinions and vision correction preferences. Contact Lens Anterior Eye. 2017;40(5):323-328. doi:10.1016/j. clae.2017.03.010

45. Morgan PB, Efron N. Prescribing soft contact lenses for astigmatism. Contact Lens Anterior Eye. 2009;32(2):97-98. doi:10.1016/j.clae.2008.10.006

46. Igras E, O'Caoimh R, O'Brien P, Power W. Patient experience of laser in situ keratomileusis and monocular small-aperture corneal inlay implantation for the surgical compensation of presbyopia and additional ametropia. Clin Experiment Ophthalmol. 2016;44 (8):728-730. doi:10.1111/ceo.12755

47. Geffen D. Presbyopia: the State of Surgical Correction. Rev Cornea Contact Lenses. 2018:20-24.

48. Ahn JH, Kim DH, Shyn KH. Investigation of the changes in refractive surgery trends in Korea. Korean $J$ Ophthalmol. 2018;32(1):8-15. doi:10.3341/kjo.2017.0010

49. Hossain P, Barbara R. The future of refractive surgery: presbyopia treatment, can we dispense with our glasses? Eye. 2021;35:359-361. doi:10.1038/s41433-020-01172-8

50. Kuo IC. Trends in refractive surgery at an academic center: 2007-2009. BMC Ophthalmol. 2011;11(1):1-6. doi:10.1186/ 1471-2415-11-11

51. Venter JA, Pelouskova M, Bull CE, Schallhorn SC, Hannan SJ. Visual outcomes and patient satisfaction with a rotational asymmetric refractive intraocular lens for emmetropic presbyopia. J Cataract Refract Surg. 2015;41(3):585-593. doi:10.1016/j. jcrs.2014.06.035

52. Levinger E, Trivizki O, Pokroy R, Levartovsky S, Sholohov G, Levinger S. Monovision surgery in myopic presbyopes: visual function and satisfaction. Optometry Vision Sci. 2013;90 (10):1092-1097. doi:10.1097/OPX.0000000000000002

53. Mahrous A, Ciralsky JB, Lai EC. Revisiting monovision for presbyopia. Curr Opin Ophthalmol. 2018;29(4):313-317. doi:10.1097/ICU.0000000000000487

54. Steinert RF. Visual outcomes with multifocal intraocular lenses. Curr Opin Ophthalmol. 2000;11(1):12-21. doi:10.1097/ 00055735-200002000-00004

55. Gundersen KG, Potvin R. Comparing Visual Acuity, Low Contrast Acuity and Contrast Sensitivity After Trifocal Toric and Extended Depth of Focus Toric Intraocular Lens Implantation. Clin Ophthalmol. 2020;14:1071. doi:10.2147/ OPTH.S253250

56. Liang Y-L, Jia S-B. Clinical application of accommodating intraocular lens. Int $J$ Ophthalmol. 2018;11(6):1028-1037. doi:10.18240/ijo.2018.06.22

57. Alió JL, Alió Del Barrio JL, Vega-Estrada A. Accommodative intraocular lenses: where are we and where we are going. Eye and Vision. 2017;4(1):16. doi:10.1186/s40662-017-0077-7

58. American Academy of Ophthalmology. Light Adjustable Intraocular lenses - EyeWiki. Available from: https://eyewiki. aao.org/Light_Adjustable_Intraocular_lenses. Accessed 16 December, 2020.

59. Levinger E, Levinger S, Mimouni M, et al. Unilateral refractive lens exchange with a multifocal intraocular lens in emmetropic presbyopic patients. Curr Eye Res. 2019;44(7):726-732. doi:10.1080/02713683.2019.1591460

60. Chang JS, Ng JC, Lau SY. Visual outcomes and patient satisfaction after presbyopic lens exchange with a diffractive multifocal intraocular lens. $J$ Refractive Surg. 2012;28(7):468-474. doi:10.3928/1081597X-20120612-01
61. Cochener B, Fernández-Vega L, Alfonso JF, Maurel F, Meunier J, Berdeaux G. Spectacle independence and subjective satisfaction of ReSTOR ${ }^{\circledR}$ multifocal intraocular lens after cataract or presbyopia surgery in two European countries. Clin Ophthalmol. 2010;4:81

62. Gibbons A, Ali TK, Waren DP, Donaldson KE. Causes and correction of dissatisfaction after implantation of presbyopia-correcting intraocular lenses. Clin Ophthalmol. 2016;10:1965. doi:10.2147/OPTH.S114890

63. Schmid R, Luedtke H. A Novel Concept of Correcting Presbyopia: first Clinical Results with a Phakic Diffractive Intraocular Lens. Clin Ophthalmol. 2020;14:2011. doi:10.2147/ OPTH.S255613

64. Davidson RS, Dhaliwal D, Hamilton DR, et al. Surgical correction of presbyopia. J Cataract Refract Surg. 2016;42(6):920-930. doi:10.1016/j.jcrs.2016.05.003

65. Stahl JE. Conductive keratoplasty for presbyopia: 1-year results. $J$ Refractive Surg. 2006;22(2):137-144. doi:10.3928/1081-597X20060201-10

66. McDonald MB, Durrie D, Asbell P, Maloney R, Nichamin L. Treatment of presbyopia with conductive keratoplasty ${ }^{\circledR}$ : six-month results of the 1-year united states FDA clinical trial. Cornea. 2004;23(7):661-668. doi:10.1097/01.ico.0000126321.13143.a0

67. Dexl AK, Seyeddain O, Riha W, et al. One-year visual outcomes and patient satisfaction after surgical correction of presbyopia with an intracorneal inlay of a new design. J Cataract Refract Surg. 2012;38(2):262-269. doi:10.1016/j.jcrs.2011.08.031

68. American Academy of Ophthalmology. Updated To FDA Class 1 Device Recall: raindrop Near Vision Inlay may raise risk of corneal haze. Available from: https://www.aao.org/headline/fdaalert-raindrop-near-vision-inlay-may-raise-ris. Accessed 8 February, 2021.

69. Dexl AK, Jell G, Strohmaier C, et al. Long-term outcomes after monocular corneal inlay implantation for the surgical compensation of presbyopia. J Cataract Refract Surg. 2015;41(3):566-575. doi:10.1016/j.jcrs.2014.05.051

70. Vukich JA, Durrie DS, Pepose JS, Thompson V, van de Pol C, Lin L. Evaluation of the small-aperture intracorneal inlay: three-year results from the cohort of the US Food and Drug Administration clinical trial. J Cataract Refract Surg. 2018;44 (5):541-556. doi:10.1016/j.jcrs.2018.02.023

71. Ayoubi MG, Leccisotti A, Goodall EA, McGilligan VE, Moore TC. Femtosecond laser in situ keratomileusis versus conductive keratoplasty to obtain monovision in patients with emmetropic presbyopia. J Cataract Refract Surg. 2010;36(6):997-1002. doi:10.1016/j.jcrs.2009.12.035

72. Lafosse E, Wolffsohn J, Talens-Estarelles C, García-Lázaro S. Presbyopia and the aging eye: existing refractive approaches and their potential impact on dry eye signs and symptoms. Contact Lens Anterior Eye. 2020;43(2):103-114. doi:10.1016/j. clae.2019.08.005

73. Farid M, Steinert RF. Patient selection for monovision laser refractive surgery. Curr Opin Ophthalmol. 2009;20(4):251-254. doi:10.1097/ICU.0b013e32832a0cdb

74. Alió JL, Amparo F, Ortiz D, Moreno L. Corneal multifocality with excimer laser for presbyopia correction. Curr Opin Ophthalmol. 2009;20(4):264-271. doi:10.1097/ ICU.0b013e32832a7ded

75. Hipsley A, Hall B, Rocha KM. Scleral surgery for the treatment of presbyopia: where are we today? Eye and Vision. 2018;5(1):4. doi:10.1186/s40662-018-0098-x

76. Wolffsohn JS, Leteneux-Pantais C, Chiva-Razavi S, et al. Social Media Listening to Understand the Lived Experience of Presbyopia: systematic Search and Content Analysis Study. J Med Internet Res. 2020;22(9):e18306. doi:10.2196/18306 
77. Hutchins B, Huntjens B. Patients' attitudes and beliefs to presbyopia and its correction. J Optom. 2020;14(2):127-132. doi:10.1016/j.optom.2020.02.001

78. Greenhills WS. The quality of life in patients with non-surgical and surgical presbyopic corrections. Philipp J Ophthalmol. 2015;40:11-17.

79. Brayton-Chung A, Tomashek D, Smith RO. Fall Risk Assessment: Development Of A Paradigm To Measure Multifocal Eyeglass Effects. Phys Occup Ther Geriatr. 2013;31 (1):47-60. doi:10.3109/02703181.2012.763200

80. Masud T, Morris RO. Epidemiology of falls. Age Ageing. 2001;30 (suppl_4):3-7. doi:10.1093/ageing/30.suppl_4.3

81. Elliott DB, The Glenn A. Fry award lecture 2013: blurred vision, spectacle correction, and falls in older adults. Optom Vis Sci. 2014;91(6):593-601. doi:10.1097/OPX.0000000000000268

82. Sander R. Multifocal glasses and falls. Nurs Older People. 2010;22(7):15.

83. Lord SR, Dayhew J, Sc BA, Howland A. Multifocal glasses impair edge-contrast sensitivity and depth perception and increase the risk of falls in older people. J Am Geriatr Soc. 2002;50 (11):1760-1766. doi:10.1046/j.1532-5415.2002.50502.x

84. Vale A, Scally A, Buckley JG, Elliott DB. The effects of monocular refractive blur on gait parameters when negotiating a raised surface. Ophthalmic Physiol Optics. 2008;28(2):135-142. doi:10.1111/j.1475-1313.2008.00543.x

85. Elliott DB, Chapman GJ. Adaptive gait changes due to spectacle magnification and dioptric blur in older people. Invest Ophthalmol Vis Sci. 2010;51(2):718-722. doi:10.1167/iovs.094250

86. Haran MJ, Cameron ID, Ivers RQ, et al. Effect on falls of providing single lens distance vision glasses to multifocal glasses wearers: VISIBLE randomised controlled trial. BMJ. 2010;340 (may25 1):c2265. doi:10.1136/bmj.c2265

87. Elliott DB, Hotchkiss J, Scally AJ, Foster R, Buckley JG. Intermediate addition multifocals provide safe stair ambulation with adequate 'short-term'reading. Ophthalmic Physiol Optics. 2016;36(1):60-68. doi:10.1111/opo.12236

88. Optometry Times. Treatments for presbyopia coming soon. Available from: https://www.optometrytimes.com/view/trea ments-for-presbyopia-coming-soon. Accessed 9 February, 2021.

89. Renna A, Vejarano LF, De la Cruz E, Alió JL. Pharmacological treatment of presbyopia by novel binocularly instilled eye drops: a pilot study. Ophthalmol Therapy. 2016;5(1):63-73. doi:10.1007/ s40123-016-0050-x

90. Abdelkader A. Improved presbyopic vision with miotics. Eye Contact Lens. 2015;41(5):323-327. doi:10.1097/ICL.00000000 00000137

91. Visus therapeutics launches and announces clinical development program for novel presbyopia eye drop. Available from: https:// apnews.com/press-release/business-wire/products-and-servicesownership-changes-business-patent-acquisitions-product-testing -6b4e855ea0fd4a358b9c8a94379b50d3. Accessed 8 February, 2021.

92. Allergan, an AbbVie Company, Announces Positive Phase 3 Topline Results for Investigational AGN-190584 for the Treatment of Presbyopia | abbVie News Center. Available from: https://news.abbvie.com/news/press-releases/allergan-an-abbviecompany-announces-positive-phase-3-topline-results-forinvestigational-agn-190584-for-treatment-presbyopia.htm. Accessed 8 February, 2021.

93. ClinicalTrials.gov. A Phase 3 Efficacy Study of AGN-190584 in Participants With Presbyopia. Available from: https://clinical trials.gov/ct2/show/NCT03857542. Accessed 8 February, 2021.

94. ClinicalTrials.gov. A Safety, Efficacy and Pharmacokinetic Study of AGN-199201 and AGN-190584 in Patients With Presbyopia. Available from: https://clinicaltrials.gov/ct2/show/NCT02780115. Accessed 8 February, 2021.
95. Presbyopia Therapies press release 2018; 2019. Available from: https:/www.prnewswire.com/news-releases/presbyopia-therapiesannounces-primary-safety-and-efficacy-endpoints-met-in-a-phaseiib-study-of-its-topical-prx-ophthalmic-solution-for-the-treatmentof-presbyopia-300688070.html. Accessed May 14, 2021.

96. Ocuphire Pharma Nyxol® Eye Drops. Available from: https://www. ocuphire.com/product-pipeline/nyxol. Accessed 11 February, 2021.

97. ClinicalTrials.gov. Safety and efficacy of nyxol with pilocarpine eye drops in subjects with presbyopia. Available from: https://clinical trials.gov/ct2/show/NCT04675151. Accessed 8 February, 2021.

98. Orasis Pharmaceuticals Announces CSF-1 Eye Drop Successfully Met Primary Endpoint in Phase 2b Clinical Study in Presbyopia. Available from: https://www.globenewswire.com/news-release /2019/10/10/1928125/0/en/Orasis-Pharmaceuticals-AnnouncesCSF-1-Eye-Drop-Successfully-Met-Primary-Endpoint-in-Phase -2b-Clinical-Study-in-Presbyopia.html. Accessed 8 February, 2021.

99. ClinicalTrials.gov. A Multi-Center, Double-Masked Evaluation of the Efficacy and Safety of CSF-1 in the Treatment of Presbyopia. Available from: https:/clinicaltrials.gov/ct2/show/NCT03885011. Accessed 8 February, 2021.

100. Eyewire News. FDA Approves Eyenovia's IND Application for MicroLine for Presbyopia, Allowing for Phase 3 Trials. @eyewiretoday. Available from: https://eyewire.news/articles/fdaapproves-eyenovias-ind-application-for-microline-for-presbyopiaallowing-for-phase-3-trials/. Accessed 11 February, 2021.

101. ClinicalTrials.gov. Safety \& efficacy of pilocarpine eye solutions for temporary improvement of near vision in presbyopic adults. Available from: https:/clinicaltrials.gov/ct2/show/NCT04657172. Accessed 8 February, 2021.

102. Grzybowski A, Markeviciute A, Zemaitiene R. A review of pharmacological presbyopia treatment. Asia Pacific J Ophthalmol. 2020;9(3):226. doi:10.1097/APO.0000000000000297

103. Benozzi G, Perez C, Leiro J, Facal S, Orman B. Presbyopia treatment with eye drops: an eight year retrospective study. Transl Vis Sci Technol. 2020;9(7):25.

104. Abdelkader A, Kaufman HE. Clinical outcomes of combined versus separate carbachol and brimonidine drops in correcting presbyopia. Eye Vis. 2016;3:31. doi:10.1186/s40662-016-0065-3

105. Richdale K. UNR844 ophthalmic solution for the topical treatment of presbyopia: results of a Phase II randomised controlled trial. Presented Acad Home. 2020;7:2020.

106. Korenfeld MS, Robertson SM, Stein JM, et al. Topical lipoic acid choline ester eye drop for improvement of near visual acuity in subjects with presbyopia: a safety and preliminary efficacy trial. Eye. 2021. doi:10.1038/s41433-020-01391-z

107. ViewPoint Therapeutics press release 2018. Available from: https://www.viewpointtherapeutics.com/new-blog/2018/3/5/view point-therapeutics-raises-35-million-in-series-b-financing. Accessed 8 September, 2019.

108. Stival LR, Figueiredo MN, Santhiago MR. Presbyopic excimer laser ablation: a review. J Refractive Surg. 2018;34(10):698-710. doi:10.3928/1081597X-20180726-02

109. Schallhorn SC, Teenan D, Venter JA, et al. Monovision LASIK versus presbyopia-correcting IOLs: comparison of clinical and patient-reported outcomes. $J$ Refractive Surg. 2017;33 (11):749-758. doi:10.3928/1081597X-20170721-03

110. Waring GO, Waring GO. Correction of presbyopia with a small aperture corneal inlay. J Refractive Surg. 2011;27(11):842-845. doi:10.3928/1081597X-20111005-04

111. Torricelli AA, Junior JB, Santhiago MR, Bechara SJ. Surgical management of presbyopia. Clin Ophthalmol. 2012;6:1459. doi:10.2147/OPTH.S35533

112. ClinicalTrials.gov. A Study of Safety and Efficacy of UNR844 Chloride (UNR844-Cl) Eye Drops in Subjects With Presbyopia. Available from: https:/clinicaltrials.gov/ct2/show/NCT03809611. Accessed 24 February, 2021. 


\section{Publish your work in this journal}

Clinical Ophthalmology is an international, peer-reviewed journal covering all subspecialties within ophthalmology. Key topics include: Optometry; Visual science; Pharmacology and drug therapy in eye diseases; Basic Sciences; Primary and Secondary eye care; Patient Safety and Quality of Care Improvements. This journal is indexed on PubMed

Submit your manuscript here: https://www.dovepress.com/clinical-ophthalmology-journal
Central and CAS, and is the official journal of The Society of Clinical Ophthalmology (SCO). The manuscript management system is completely online and includes a very quick and fair peer-review system, which is all easy to use. Visit http://www.dovepress.com/ testimonials.php to read real quotes from published authors. 